\title{
Structure and mechanical properties of AFS sandwiches studied by in-situ compression tests in X-ray michrotomography
}

\author{
By L. Salvo, * P. Belestin, E. Maire, M. Jacquesson, C. Vecchionacci, \\ E. Boller, M. Bornert, P. Doumalin
}

Al foam core / Al alloy skins sandwiches have potential for application in light weight structures. Recently, the foaming processes have improved and large, thick and 3D-shape panels can be produced using the precursor technology. The microstructure of an AFS sandwich is analysed in this paper at a microscale and a mesoscale using X-ray tomography and conventional SEM analysis. The main deformation mechanism of the core under compression is also studied thanks to in situ test. It is shown that the foam first present plastic buckling and then walls rupture. This is well correlated to the microstructure of the constitutive material of the core.

\section{Introduction}

One of the interests of aluminium foams is their integration in sandwiches. Two main routes are available to produce sandwiches. The first one consists in bonding with adhesive the foams to aluminium, steel or composites sheets or tubes. In the second, the sandwich structure, is produced in a one step process: a precursor of $\mathrm{Al}$ and $\mathrm{TiH}_{2}$ is co-laminated with $\mathrm{Al}$ sheet and then foamed in a furnace. ${ }^{[1]}$ The first process presents the advantage to allow a wide combination of materials (face and core) and also a large choice in dimensions. However the main drawback is the limitation in shape of the structure when panels are considered: indeed in this case only flat panels can be produced. The second technique presents the advantage to allow the manufacturing of non flat panels. The bonding between the face and the core is very good in this case and there is improvement in production time and cost. The Aluminium Foam Sandwich (AFS) investigated in this study was produced using this latter technique with a new alloy for the foam part. In this paper we investigated the structure of the AFS sandwich at various scales: at the scale of the interface between the aluminium face and the foam, at the microstructural scale in order to characterise the constitutive material in the foam and at a mesoscale in order to characterise the cell size distribution and the cell wall thickness distribution. The latter characterisation was performed on several samples in order to get statistical information. The compression behaviour of aluminium foams have
[*] Dr. L. Salvo

G.P.M.2 / U.M.R. 5010

I.N.P. Grenoble

B.P.46 38402 Saint Martin d'Hères, France

E-mail:

P. Belestin, Dr. E. Maire

G.E.M.P.P.M.

I.N.S.A. Lyon

20 Av. A. Einstein, 69621 Villeurbanne cedex, France

Dr. M. Jacquesson, Dr. C. Vecchionacci

Centre National d'Etudes Spatiales

CNES Direction des Lanceurs

Rond-Point de l'Espace 91023, Evry cedex - France

E. Boller

European Synchrotron Radiation Facility

Grenoble, France

Dr. M. Bornert

LMS, Ecole Polytechnique

91128 Palaiseau Cedex, France

Dr. P. Doumalin

LMS, Université de Poitiers

86962 Futuroscope Chasseneuil cedex, France

[**] The authors would first like to thank H.W. Seeliger for providing material. They would also like to thank J. Baruchel and P. Cloetens from ESRF. A free software ImageJ was used to perform Image analysis and Slicer was used for $3 D$ rendering. 
been extensively studied using conventional technique and tomography in order to identify the main deformation mechanisms. ${ }^{[2-7]}$ Since the foam investigated here is made with a new alloy for which the deformation modes are not so well known, we also performed such an analysis. A 3D extension of the classical field measurement by $2 \mathrm{D}$ image correlation has been recently developed in ${ }^{[8]}$. It is used in the present study to characterise the deformation field from the tomography images.

\section{Experimental}

The AFS material was produced by ALM GmbH from an aluminium foam precursor (an $\mathrm{Al} 6 \mathrm{wt} \% \mathrm{Si} 4 \mathrm{wt} \% \mathrm{Cu}$ alloy) and a 6060 aluminium sheet of $0.9-1 \mathrm{~mm}$ in thickness. The experimental panel had dimensions of $1000 \mathrm{~mm} \times 600 \mathrm{~mm}$ and the total maximum height of $27,5 \mathrm{~mm}: 0.9-1 \mathrm{~mm}$ for the face material and about 25.5 for the aluminium foam core. 5 small pieces $(30 \times 30 \times 27.5 \mathrm{~mm})$ were extracted from the panel at various locations in order to perform a statistical analysis of the mesoscale structure. We performed standard SEM analysis of the face/core interface and of the foam microstructure. Furthermore we performed X-ray tomography on the ID 19 beam line at the ESRF with two resolutions: a high resolution of $0.7 \mu \mathrm{m}$ was used to focus on the face/core interface and a medium resolution $(30 \mu \mathrm{m})$ was used to study the foam architecture and its reproducibility within the panel. The energy used was $35 \mathrm{keV}$ and a minimum of 1000 projections were taken over $180^{\circ}$. This ensured a good reconstruction and a high quality of the images. The compression of the foam was performed on a dedicated device which is directly mounted on the tomography set up ${ }^{[9]}$. This allowed us to perform a compression test and scans for various values of the strain and therefore to identify the deformation mechanisms in 3D.

\section{Structural Characterization of the AFS Sandwich}

\subsection{Interface}

As mentioned in the previous section, we performed a tomography analysis of the interface between the foam and the aluminium sheet at high resolution. Figure 1 presents a 2D section extracted from the reconstructed volume: this micrograph is representative of what can be seen in the sample. The interface can be distinguished at the bottom of the image. It is free of visible defects. The apparent bonding between the core and the sheet seems to be excellent. No defect could be seen through the volume except some rupture of the second phase in the core near the interface.

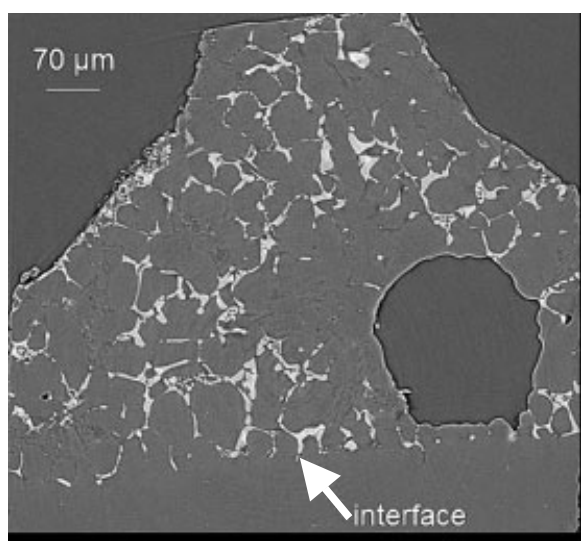

Fig 1. 2D section of the interface between the foam and the aluminium sheet obtained using $X$ ray microtomography (1 $\mu$ m resolution).

\subsection{Constitutive Material}

As mentioned earlier, the constitutive material of the precursor is a $\mathrm{Al} 6 \mathrm{wt} \% \mathrm{Si} 4 \mathrm{wt} \% \mathrm{Cu}$ alloy which should only contain at the equilibrium state, the two phases $(\mathrm{Al})+(\mathrm{Si})$ according to the ternary phase diagram. Figure 2 presents a $2 \mathrm{D}$ zoom of a $2 \mathrm{D}$ section in the foam. It shows various phases in the constitutive material:

- some Si lamellae can be seen (grey) which are part of the eutectic $(\mathrm{Al})+(\mathrm{Si})$.

- Cu rich phases can also be seen in white: the $1 \mu \mathrm{m}$ resolution do not allow to distinguish the two phases of the eutectic $(\mathrm{Al})+\left(\mathrm{Al}_{2} \mathrm{Cu}\right)$ which is easily seen in SEM as it can be seen in the zoom. This eutectic is formed owing to non equilibrium solidification: a simple analysis assuming no diffusion in the solid phase allows to calculate that the amount of non equilibrium eutectic should be about $7.8 \%$, which is roughly what we measure on the micrographs.

- Other phases rich in Fe are present (as shown in the SEM zoom in Fig. 2): these intermetallic phases are located inside the $(\mathrm{Al})+\left(\mathrm{Al}_{2} \mathrm{Cu}\right)$ eutectic and their shape look more like platelets than needles.

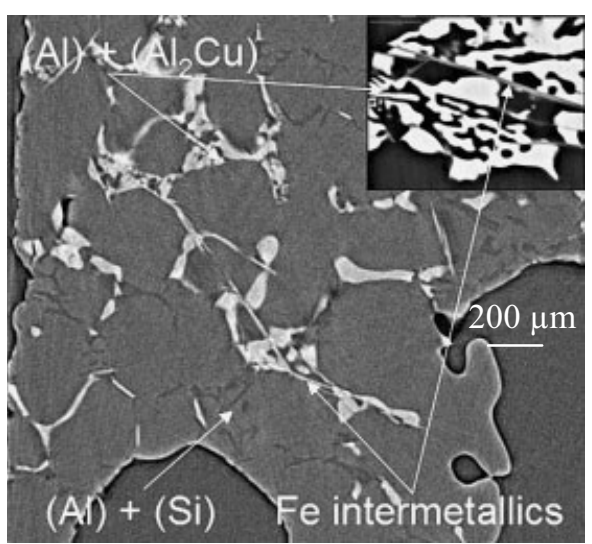

Fig 2. 2D section of the foam microstructure obtained with SEM at a high magnification: various phases can be seen. 


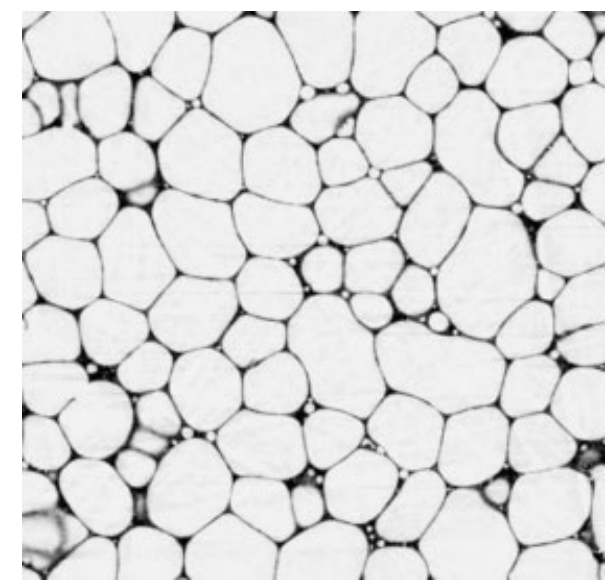

Fig 3. 2D section extracted from the $3 D$ data obtained for the foam by microtomography: the width of the sample is $\sim 25 \mathrm{~mm}$.

A complete characterisation of a foam needs the determination of several parameters: among them the first one is the global density. The global density is not enough and often a local density distribution is used. ${ }^{[10]}$ We performed such an analysis using a size of averaging box of $50 \times 50 \times 50$ voxels: this corresponds approximately to the mean cell size. Figure 4 presents the normalised local density histogram for the five samples : in the legend is indicated the mean relative density and the scatter due to the variation in the threshold. As it can be seen the mean relative density is quite homogeneous among the five samples and the local density histogram are quite similar. The second parameter to determine is the cell size distribution. This parameter is not easy to retrieve when cell walls present some cracks. One way to obtain this cell size distribution is to use 3D granulometry with a octahedron as a structural element: this is very efficient for equiaxed structures (in this case it gives an equivalent diameter of spherical shape) and gives also an information on the smallest dimension in a non equiaxed structure. ${ }^{[11]}$ Since Figure 3 shows that the cells are mainly equiaxed, this technique should give us a good idea of the cell size distribution. At least, it can be used efficiently to compare these distributions between the different samples of the present study.

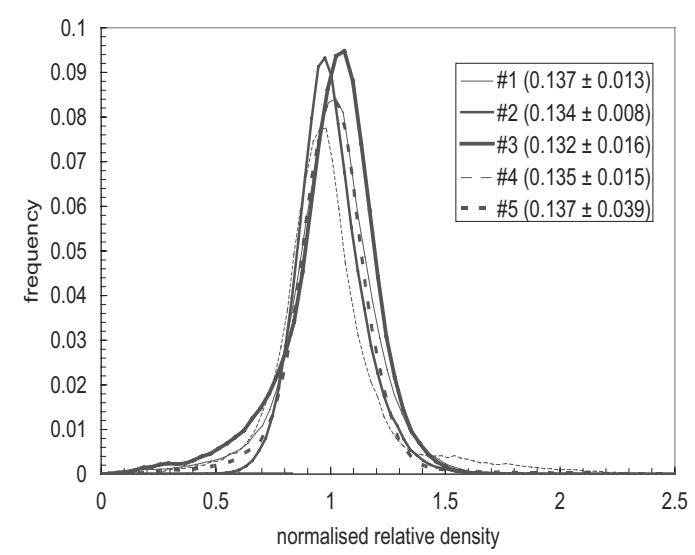

Fig 4. Normalised local density histogram: mean relative density values are given in the legend for each sample.

\subsection{Architecture of the Foam}

Figure 3 presents a 2D section of the foam extracted from a tomographic reconstruction at a resolution of $30 \mu \mathrm{m}$. As it can be seen, the cells are rather polyhedral in shape and present a quite homogeneous size. The 3D investigation of the volume shows some little cracks in the cell walls, cracks often observed in $\mathrm{TiH}_{2}$ foams.

Figure 5 presents the cell size distribution (the frequency has been normalised by the volume of each class in order to highlight large cells) for the five samples extracted from the panel. A mean cell size of about $3 \mathrm{~mm}$ is measured for all samples which indicates a good reproducibility of the panel. However, in two particular samples (\# 3 and \# 5), cells as large as $6 \mathrm{~mm}$ can be found. The 3D granulometry can also be performed on the aluminium in order to extract cell wall thickness and the edges thickness. Figure 6 shows that for three of the five samples (\# 2, \# 3 and \# 5), the curve seems to present two convoluted peaks: the first one is due to cell wall thickness and the other is basically the struts thickness. Deconvoluting the peaks allows to give an estimation of the mean cell wall thickness: a value of $0.18 \mathrm{~mm} \pm 0.03 \mathrm{~mm}$ is obtained. The ratio of the two peaks allows calculating the $\phi$ factor (solid fraction in the cell edge ${ }^{[12]}$ ): values in between 0.50 and 0.60 have been found for the samples.

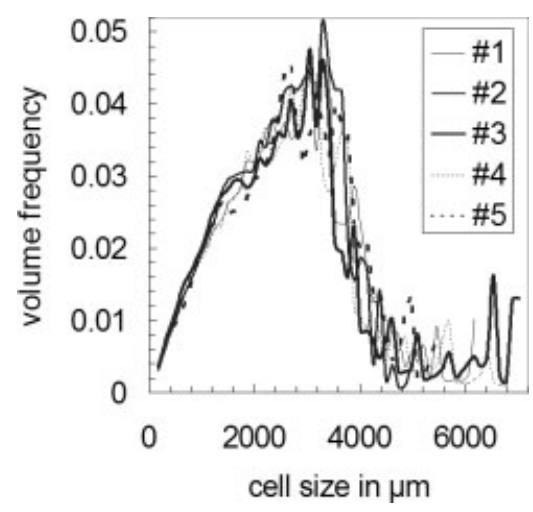

Fig 5. Cell size distribution in the five samples obtained with 3D granulometry analysis on the pores.

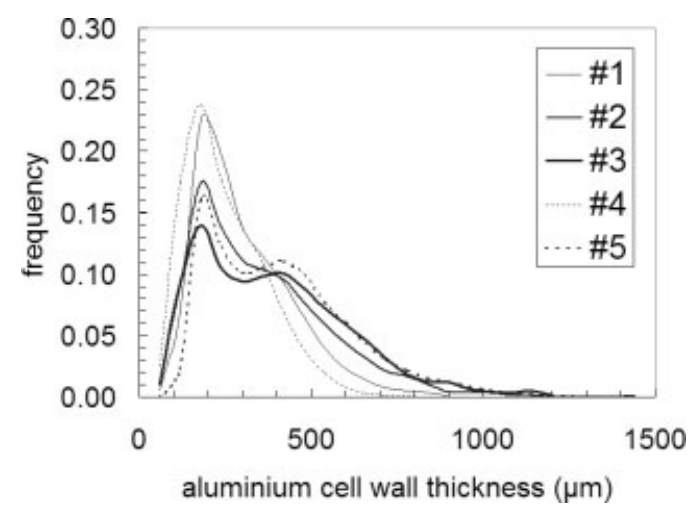

Fig 6. Aluminium thickness distribution obtained with 3D granulometry analysis on the constitutive material. 


\section{In-situ Deformation of the Foam}

\subsection{Qualitative Information}

In order to determine the main deformation mechanism of the foam, we performed an in situ compression test using a specific device developed for in situ tomography. ${ }^{[8]}$ Since tomography is non destructive this allows to study in $3 \mathrm{D}$ the main deformation mechanism. We performed 4 scans as indicated by the black circle on Figure 7. The stress-strain curve shows a large decrease in stress after the first peak which may indicate that some rupture occurs in the foam as it has been observed in other foams. ${ }^{[5]}$ As expected, the foam presents a high localisation of strain during the compression test. Figure 7 presents also 2D sections extracted in the middle of the volume for the four scans. As it can be seen there is a clear evidence of plastic buckling of the cell walls when the stress is at its maximum (see black arrow in (2)). It seems that rupture of the cell walls occurs in (3), which explains the large decrease in stress. Lastly in (4) a whole band of cells has crushed as indicated by the arrows. The rupture of the walls is due to the nature of the constitutive material which contains a large amount of non ductile second phase particles as shown previously.
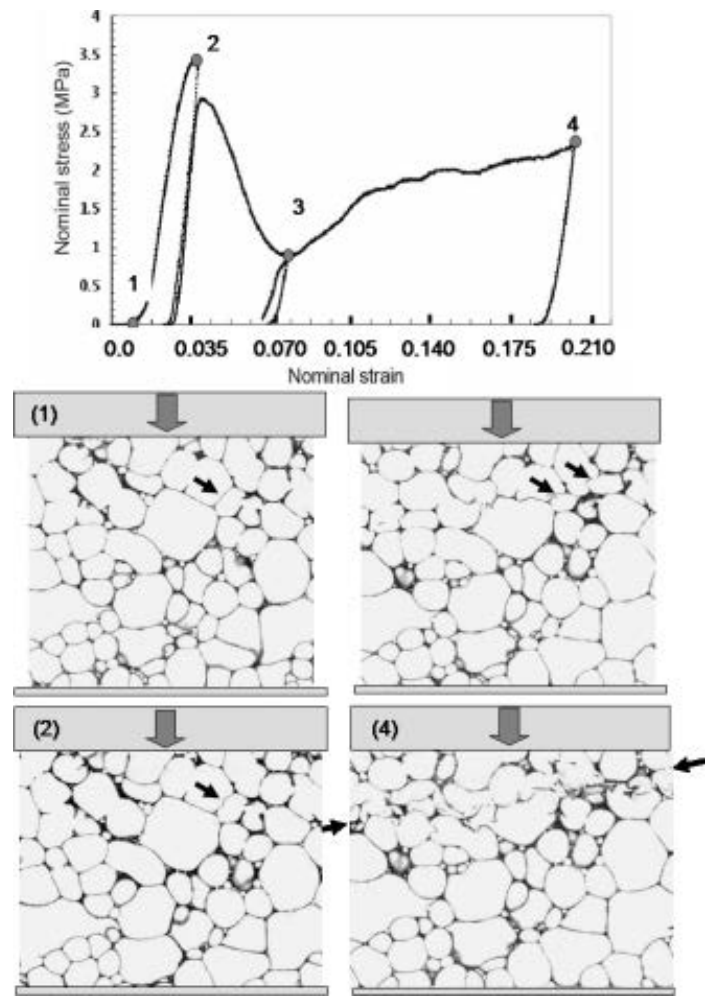

Fig 7. Stress-strain curve during in situ compression tests: 4 scans have been performed on the same sample at various strains as indicated in the graph by the numbers (1) to (4). The $2 D$ slices extracted from the $3 D$ volumes show the main deformation mechanisms for every stage. The width of the sample is $\sim 25 \mathrm{~mm}$.

\subsection{Quantitative Information}

Quantitative information of strain during the in situ compression testing can be studied using strain mapping. This has already been investigated on foams in $2 \mathrm{D}^{[12]}$ but less in $3 \mathrm{D}$. We performed this analysis in $3 \mathrm{D}$ and the principle is to compare images of the same sample in two different configurations to get the displacement field relating the first to the second. This is done by optimizing a correlation coefficient which measures the similarity of the grey level distribution in small domains around the corresponding positions in the two images, an optimal value of this coefficient corresponding to patterns that match best, which are likely to correspond to the same material points. This technique derives from the 2D version described in the literature. ${ }^{[14]}$ The correlation coefficient is calculated on a 3D (instead of 2D) domain. It has already been used to characterize the deformation of foams. ${ }^{[7,15]}$ One can refer to this last article to get a complete description of the mathematical framework used. In the present study, the local movements are assumed to be pure translations, and subvoxel accuracy is obtained by means of grey level interpolation in the deformed image. The used correlation domains are $40^{3}$ voxels, which roughly represents $1 / 10^{\text {th }}$ of the size of the sample. These displacement measurements are performed at all points on a regular $10 \times 10 \times 10$ grid in the sample. The $3 \mathrm{D}$ strain mapping is obtained by interpolation and derivation of this discrete displacement map. Note that local strain values are relative to a 40 voxels gage length, i.e. $1.2 \mathrm{~mm}$.

Figure 8 presents the results obtained between state 2 and 3 (see Fig. 7): the local strain histogram through the volume is plotted. The real nominal macroscopic strain is also mentioned. Furthermore a 3D rendering of the complete local strain field (strain along the compression axis) is shown in the left and a 3D rendering of a selection of the same strain field only showing values larger than the macroscopic strain is shown in the right of the figure. The correspondence between strain value and the grey level is also indicated below the local strain axis. It is clear from the histogram and from

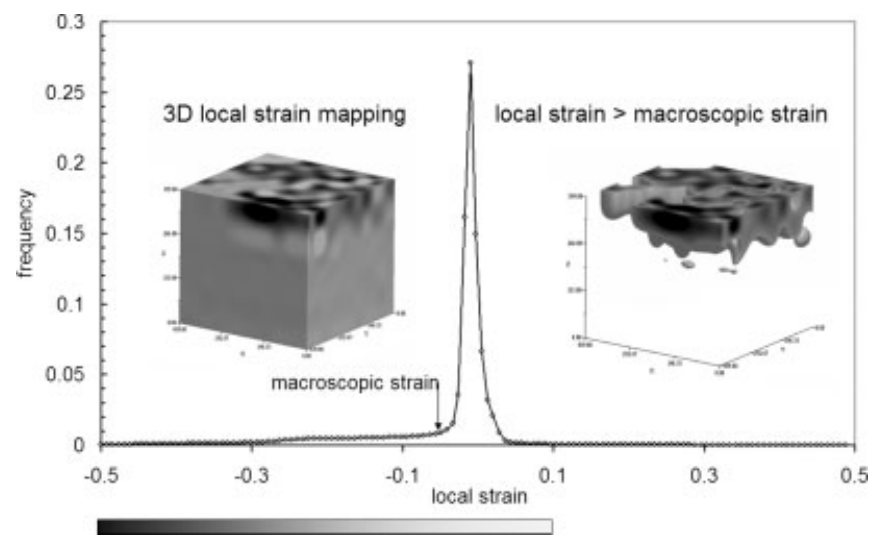

Fig 8. 3D strain mapping between state 2 and 3: histogram of the local strain within the volume. $3 D$ rendering of the local strain is presented on the right and on the left only local strain higher than the macroscopic one are presented in the $3 D$ rendering. The height of the sample is approximately $24 \mathrm{~mm}$. 
the $3 \mathrm{D}$ rendering that there is strain localisation at the top of the sample. This is in good agreement with the qualitative results shown in Fig. 7. The bottom part of the sample is absolutely not deformed as revealed by this strain measurement.

\section{Conclusion}

We investigated the structure and the compression behaviour of an AFS sandwich produced with a new alloy (Al6\%$\mathrm{Si} 4 \% \mathrm{Cu})$. The structural characterization was performed on several samples extracted from the panel. It leads to the following conclusions:

- The interface between the core and the face is excellent: no defects were found

- The local density distribution indicates a quite homogeneous foam with a mean cell size of $3 \mathrm{~mm}$, a mean cell wall thickness of $180 \mu \mathrm{m}$.

- The constitutive material presents $(\mathrm{Al})+(\mathrm{Al} 2 \mathrm{Cu})$ eutectic due to non equilibrium solidification and also some Fe intermetallics.

- Under compression the foam present first a plastic buckling behaviour of the walls followed by a rupture of these walls: this lead to a large decrease of the stress after the peak stress.

- The 3D strain mapping reveals that the strain is highly localized even in the very first step of strain.

Received: March 23, 2004

[1] H. W. Seeliger, in Cellular Metals and Metal Foaming Technology, Eds.: J. Banhart, M. F. Ashby, N. Fleck, MIT Verlag Bremen, 2001, p. 5.

[2] A. H. Benaouali, L. Froyen Cellular Metals and Metal Foaming Technology, Eds.: J. Banhart, M. F. Ashby, N. Fleck, MIT Verlag Bremen, 2001, p. 269.
[3] H. Bart-Smith, A. F. Bastwaros, D. R. Mumm, A. G. Evans, D. J. Sypeck, H.N.G Wadley, Acta Mater. 1998, 46,3582 .

[4] B. Krizst, B. Foroughi, K. Faure, H. P. Degisher, in Metal Foams and Porous Metal Structures, Eds.: J. Banhart, M. F. Ashby, N. Fleck, MIT Verlag Bremen, 1999, p 241.

[5] E. Maire, A. Elmoutaouakkil, A. Fazekas, L. Salvo, MRS Bulletin 2003, 28, 284.

[6] G. Gioux, T. M. McCormack, L. J. Gibson, Int. J. Mech. Sci. 2000, 42, 1097.

[7] E. Jasiunienë, J. Goebbels, B. Illerhaus, P. Löwe, A. Kottar, in Cellular Metals and Metal Foaming Technology, Eds.: J. Banhart, M. F. Ashby, N. Fleck, MIT Vertlag Bremen, 2001, p. 251.

[8] M. Bornert, P. Doumalin, E. Maire, Mesure tridimensionnelle des champs de déformation par corrélation d'images microtomographiques, Proceedings of Photoméca 2004, ed. by J. J. Orteu, to appear.

[9] J. Y. Buffière, E. Maire, P. Cloetens, G. Lormand, R. Fougères, Acta Mater. 1999, 47, 1613.

[10] H. P. Degisher, A. Kottar in Metal Foams and Porous Metal Structures, Eds.: J. Banhart, M. F. Ashby, N. Fleck, MIT Verlag Bremen, 1999, p. 213.

[11] A. Elmoutaouakkil, L. Salvo, E. Maire, G. Peix, Adv. Eng. Mater. 2002, 4, 334.

[12] L. J. Gibson, M. F. Ashby, "Cellular Solids: Structure and Properties", Cambridge, UK: Cambridge Univ. Press, $2^{\text {nd }} \mathrm{ed}$. (1997).

[13] H. Bart-Smith, A.-F. Bastawros, D. R. Mumm, A. G. Evans, D. J. Sypeck, H.N.G. Wadley Acta Mater. 1998, $46,3583$.

[14] H. A Bruck, S. R McNeill, M. A Sutton, W. H Peters. Experimental Mechanics 1989, 29, 261.

[15] B. K. Bay, T. S. Smith, D. P. Fyhrie ,M. Saad. Experimental Mechanics 1999, 39, 218. 